\title{
Applicability of Energy Conservation Policies in Turkey: A Sectoral Analysis Through the Fourier Approximation
}

\author{
Muhammed Sehid Gorus ${ }^{1}$ (1) \\ ${ }^{1}$ Ankara Yıldırım Beyazıt University, Turkey \\ Keywords: causality, energy consumption, fourier approximation, income level \\ https://doi.org/10.46557/001c.17878
}

\section{Energy RESEARCH LETTERS}

Vol. 1, Issue 4, 2020

In this paper, we test four fundamental hypotheses on the applicability of energy conservation policies, namely, conservation, neutrality, growth, and feedback. We utilize an annual dataset for sectoral levels of energy use and income level. We find that mitigating energy consumption does not decrease the economic growth.

\section{Introduction}

Energy and energy sources have a significant role in the production process since it is accepted as an input for manufacturing. Moreover, energy conservation policies can affect the production level and the economic growth of the country directly. Turkey is an energy-dependent country and meets its energy demand mostly through energy imports. This energy dependency is a burden on the Turkish economy. Thus, policymakers should take into consideration some economic measures regarding energy use. The key question in this regard is: is it possible to conduct energy conservation policies in Turkey?

In the energy economics literature, it is possible to determine the applicability of energy conservation policies through a Granger causality test between energy consumption $(E C)$ and economic growth $(Y)$. There are four main hypotheses that support this test; a) conservation, b) neutrality, c) growth, and d) feedback hypotheses. According to the conservation $(Y \rightarrow E C)$ and neutrality $(Y-E C)$ hypotheses, economic development is not affected negatively by the reduction in energy consumption level, while the growth $(E C \rightarrow Y)$ and feedback $(Y \leftrightarrow E C)$ hypotheses claim the opposite effects ${ }^{1}$ (Gorus \& Aydin, 2019).

The main goal of this study is to examine the causal linkages between sectoral energy consumption (industry, residential, services, and transport) and economic growth in Turkey for the 1971-2017 period. A recent study conducted by Gorus et al. (2019) considers Fourier terms in the causal linkages between oil imports and manufacturing production index using Turkish data. However, to our knowledge, our study is the first to consider the Fourier approximation in the relationship between sectoral energy use and income level for the Turkish economy.

The remaining part of this paper includes the following sections. Section II summarizes the related empirical liter- ature while Section III introduces the dataset and methods utilized. Section IV exhibits the empirical findings of this paper, and Section V concludes the study.

\section{Literature Review}

There is an extensive literature on the relationship between energy use and economic growth for both developed and developing countries (see Omri, 2014; Ozturk, 2010; Tiba \& Omri, 2017). However, there is a limited study on this issue regarding the sectoral analysis for the Turkish energy market.

There are several papers on the relationship between sectoral energy/electricity consumption and economic growth regarding the Turkish economy. However, these studies mostly ignore the effects of structural breaks both in the unit root testing and causality analysis. Among the preliminary studies, Terzi (1998) finds a bidirectional causal relationship between income and electricity consumption for commercial and industrial levels in the Turkish energy market. Furthermore, Jobert \& Karanfil's (2007) findings suggest support for the neutrality hypothesis for the aggregate and industrial level of energy consumption. Moreover, Kar \& Kınık (2008) show that electricity consumption Granger causes economic growth at the sectoral level.

Şahbaz \& Yanar (2013) find a one-way causality running from economic growth to total energy consumption, while sectoral level analysis provides mixed results. Besides, Usta \& Berber (2017) employ the Toda-Yamamoto Granger causality test and show evidence for the feedback hypothesis for Turkey's transport and industry sectors, Their results further support the neutrality hypothesis for agriculture and residential sectors. Apart from these studies, Gorus et al. (2019) take into consideration the Fourier terms in testing the causal linkages between oil prices, oil imports, and income level in Turkey. They find that the income level Granger causes energy imports, thus supporting the

$1 \rightarrow, \leftrightarrow$, and — denote the unidirectional, bidirectional, and no Granger causality, respectively. 
Table 1. Descriptive Statistics

\begin{tabular}{lccccccccc}
\hline Variables & Mean & Median & Max. & Min. & $\begin{array}{c}\text { Std. } \\
\text { Dev. }\end{array}$ & Skewness & Kurtosis & JB & Probability \\
\hline$G D P_{\text {total }}$ & 26.52 & 26.53 & 27.58 & 25.53 & 0.58 & 0.11 & 1.93 & 2.33 & 0.31 \\
$G D P_{\text {industry }}$ & 25.09 & 25.12 & 26.34 & 23.91 & 0.67 & 0.10 & 1.99 & 2.07 & 0.35 \\
$G D P_{\text {residential }}$ & 26.11 & 26.11 & 27.07 & 25.26 & 0.52 & 0.11 & 2.03 & 1.96 & 0.38 \\
$G D P_{\text {services }}$ & 25.79 & 25.78 & 26.74 & 24.90 & 0.50 & 0.10 & 2.10 & 1.65 & 0.44 \\
$G D P_{\text {transport }}$ & 24.11 & 24.09 & 25.32 & 22.67 & 0.73 & -0.11 & 1.95 & 2.24 & 0.33 \\
$E C_{\text {final }}$ & 10.70 & 10.73 & 11.56 & 9.69 & 0.51 & -0.14 & 1.93 & 2.40 & 0.30 \\
$E C_{\text {industry }}$ & 9.37 & 9.38 & 10.39 & 7.88 & 0.66 & -0.40 & 2.10 & 2.83 & 0.24 \\
$E C_{\text {residential }}$ & 9.63 & 9.66 & 10.01 & 9.08 & 0.24 & -0.47 & 2.24 & 2.87 & 0.24 \\
$E C_{\text {services }}$ & 7.30 & 7.10 & 9.51 & 4.91 & 1.40 & 0.23 & 1.65 & 3.98 & 0.14 \\
$E C_{\text {transport }}$ & 9.18 & 9.28 & 10.23 & 8.15 & 0.51 & 0.05 & 2.39 & 0.75 & 0.69 \\
\hline
\end{tabular}

Note: This table displays descriptive statistics for each variable. The statistics estimated are the mean, median, maximum, minimum, standard deviation (Std, Dev.), skewness, kurtosis, and the Jarque-Bera (JB). The JB test examines the null hypothesis of a normal distribution.

conservation hypothesis.

\section{Data and Methodology}

This study utilizes an annual dataset covering the period 1971-2017 for the Turkish economy. Sectoral energy consumption data and GDP data are taken from the International Energy Agency and United Nations' datasets, respectively. All the series are in natural logarithm form. Descriptive statistics of the series are displayed in the following table.

Enders \& Jones (2016) state that ignoring structural breaks in a VAR (vector autoregression) model can lead to biased results. As a result, the Granger causality test results can be misleading. In this study, we follow the methodology of Enders \& Jones (2016) to determine the causal link between the variables that consider the gradual shifts instead of sharp breaks. They incorporate the Fourier terms into the standard VAR model (Eq. 1) and obtain the following form [Eq. 2]:

$$
z_{t}=A_{0}+\sum_{i=1}^{l} A_{i} z_{t-i}+\varepsilon_{t}
$$

In the above equation, $A_{0}$ is a vector of intercepts, $A_{i}$ denotes a coefficient matrix, $\varepsilon_{t}$ is the error term, and $l$ is lag length.

$$
z_{t}=A_{0}(t)+\sum_{i=1}^{l} A_{i} z_{t-i}+\varepsilon_{t}
$$

where $A_{0}(t)=\left[\vartheta_{1}(t), \vartheta_{2}(t), \vartheta_{3}(t), \ldots, \vartheta_{n}(t)\right]^{\prime}$, while $A_{0}(t)$ denotes the deterministic term, and $\vartheta_{i}(t)$ depends on the $n$ Fourier frequencies:

$$
\vartheta_{i}(t)=a_{i}+b_{i} t+\sum_{k=1}^{n} \gamma_{\mathrm{ik}} \sin \left(\frac{2 \pi k t}{T}\right)+\sum_{k=1}^{n} \mu_{\mathrm{ik}} \cos \left(\frac{2 \pi k t}{T}\right)
$$

$T$ denotes the number of observations and $\pi=3.1415$

\section{Empirical Results}

This study utilizes an annual dataset and employs the Fourier approximation to detect the causal relationship among different types of energy use and income level at the sectoral level. Empirical results from our analysis are presented in Tables $\underline{2}$ and $\underline{3}$. Table 2 displays the unit root properties of the series based a model that accommodates both a constant and a time trend term -the Fourier ADF model proposed by Enders \& Lee (2012). The ADF unit root test is also provided. Table 3 , on the other hand, exhibits the Fourier Granger causality test results for aggregated and disaggregated levels of energy use and GDP.

We employ two unit root tests, namely the ADF and the Fourier ADF. Since the $F$-statistics are lower than the critical value, it is revealed that the Fourier terms are insignificant in the unit root analysis. Thus, this study takes into consideration the ADF unit root test results instead of the Fourier ADF test. According to the findings, GDP from transport, final energy consumption, industrial energy consumption, and residential energy consumption series have mean-reverting behavior, while the remaining series are nonstationary. We take the first differences of the nonstationary series and then conduct the Fourier Granger causality analysis between the aforementioned variables. The empirical results are presented in Table 3 .

Empirical results gathered from the causality test show that there is a one-way causal relationship from economic growth to energy consumption (conservation hypothesis) regarding aggregated data. Also, there is a unidirectional Granger causality from economic growth to energy consumption in the industrial sector. However, there is no causal linkage between these series (neutrality hypothesis) in residential, services, and transport sectors in the Turkish economy during the period 1971-2017. Overall, one can state that energy conservation policies will not affect the economic growth of this country negatively. So, the government can design and implement energy conservation policies to decrease energy consumption at the sectoral level.

Our results are in line with the empirical findings of Jobert \& Karanfil (2007), Şahbaz \& Yanar (2013) and Gorus et al. (2019) in terms of the applicability of energy conservation policies.

\section{Conclusion}

This paper explores the causal linkage between energy 
Table 2. Unit root tests results with constant and trend model

\begin{tabular}{lcccccc}
\hline & \multicolumn{3}{c}{ Fourier ADF Unit Root Test } & \multicolumn{2}{c}{ ADF Unit Root Test } \\
\cline { 2 - 5 } Variables & $k$ & Fstatistics & $\tau_{D F_{-} t}$ & Level & First Difference & Result \\
\hline$G D P_{\text {total }}$ & 5 & 4.49 & -2.59 & -2.38 & $-6.58^{* * *}$ & $\mathrm{I}(1)$ \\
$G D P_{\text {industry }}$ & 5 & 4.05 & -2.26 & -2.20 & $-5.49^{* * *}$ & $\mathrm{I}(1)$ \\
$G D P_{\text {residential }}$ & 1 & 2.17 & -2.76 & -2.96 & $-6.82^{* * *}$ & $\mathrm{I}(1)$ \\
$G D P_{\text {services }}$ & 1 & 3.39 & -2.89 & -1.10 & $-6.49^{* * *}$ & $\mathrm{I}(1)$ \\
$G D P_{\text {transport }}$ & 5 & 3.35 & $-3.75^{* *}$ & $-3.57^{* *}$ & $-5.65^{* * *}$ & $\mathrm{I}(0)$ \\
$E C_{\text {final }}$ & 5 & 3.89 & $-5.50^{* * *}$ & $-4.75^{* * *}$ & $-8.07^{* * *}$ & $\mathrm{I}(0)$ \\
$E C_{\text {industry }}$ & 1 & 0.25 & -3.84 & $-4.06^{* *}$ & $-8.67^{* * *}$ & $\mathrm{I}(0)$ \\
$E C_{\text {residential }}$ & 1 & 2.10 & -3.90 & $-3.70^{* *}$ & $-7.14^{* * *}$ & $\mathrm{I}(0)$ \\
$E C_{\text {services }}$ & 1 & 1.28 & -3.02 & -1.85 & $-6.56^{* * *}$ & $\mathrm{I}(1)$ \\
$E C_{\text {transport }}$ & 2 & 4.52 & $-4.99^{* * *}$ & -2.11 & $-5.23^{* * *}$ & $\mathrm{I}(1)$ \\
\hline
\end{tabular}

Note: In the above table, $k$ represents the number of lag length while $\tau_{D F_{-} t}$ denotes the test statistics for the Fourier ADF test. The significance of the Fourier terms can be determined by the $F$-statistics in the Fourier ADF unit root test. The critical value of the $F$-statistics is 7.78 (10\% level of significance) when $T=100$. Since the $F$-statistics are lower than the critical value, the Fourier terms are insignificant. Therefore, this study takes into consideration the ADF unit root test results. The ${ }^{* * * *}$ and ${ }^{* * *}$ show significance at the $1 \%$ and $5 \%$ levels, respectively. Finally, I(1) denotes that the variable is stationary when taken at first difference, while $\mathrm{I}(0)$ shows the variable is stationary in its level form.

Table 3. Fourier Granger causality test results

\begin{tabular}{lcc}
\hline Null Hypothesis & $x^{2}$ Statistics & Result \\
\hline$\Delta G D P_{\text {total }} \nrightarrow E C_{\text {final }}$ & $2.74^{*}$ & Conservation Hypothesis \\
$E C_{\text {final }} \nrightarrow \Delta G D P_{\text {total }}$ & 0.57 & \\
$\Delta G D P_{\text {indutry }} \nrightarrow E C_{\text {industry }}$ & $8.71^{* *}$ & Conservation Hypothesis \\
$E C_{\text {industry }} \nrightarrow \Delta G P_{\text {indutry }}$ & 0.77 & Neutrality Hypothesis \\
$\Delta G D P_{\text {residential }} \nrightarrow E C_{\text {residential }}$ & 0.75 & Neutrality Hypothesis \\
$E C_{\text {residential }} \nrightarrow \Delta G D P_{\text {residential }}$ & 0.29 & \\
$\Delta G D P_{\text {services }} \nrightarrow \Delta E C_{\text {services }}$ & 0.02 & Neutrality Hypothesis \\
$\Delta E C_{\text {services }} \nrightarrow \Delta G D P_{\text {services }}$ & 0.61 & \\
$G D P_{\text {transport }} \nrightarrow \Delta E C_{\text {transport }}$ & 0.08 & \\
$\Delta E C_{\text {transport }} \nrightarrow G D P_{\text {transport }}$ & 0.00 & \\
\hline
\end{tabular}

Note: $\Delta$ is the first difference operator, while $\chi^{2}$ statistics is the test statistics of the Fourier Granger causality test. Besides, $\rightarrow$ denotes there is no causality from the first variable to the second variable. The ${ }^{* *}$ and ${ }^{*}$ show $5 \%$ and $10 \%$ significance levels, respectively. The Fourier Granger causality test was introduced by Enders \& Jones (2016). It considers the gradual shifts instead of sharp breaks in the causality analysis.

use and GDP level at the aggregated and disaggregated level for the Turkish economy covering the period 1971-2017. For this purpose, we employ the Fourier Granger causality analysis that captures gradual structural shifts instead of sharp breaks. The empirical findings suggest that the conservation hypothesis is valid for the total energy consumption-GDP nexus. A similar kind of relationship is found for the industrial sector. However, we do not detect any causal link for the residential, services, and transport sectors, which support the neutrality hypothesis. Overall, our findings show that it is possible to decrease the energy consumption level for the Turkish economy. Policymakers should design policies that decrease energy consumption and increase energy efficiency at the national level. 


\section{REFERENCES}

Enders, W., \& Jones, P. (2016). Grain prices, oil prices, and multiple smooth breaks in a VAR. Studies in Nonlinear Dynamics \& Econometrics, 20(4), 399-419. https://doi.org/10.1515/snde-2014-0101

Enders, W., \& Lee, J. (2012). The flexible Fourier form and Dickey-Fuller type unit root tests. Economics Letters, 117(1), 196-199. https://doi.org/10.1016/j.ec onlet.2012.04.081

Gorus, M. S., \& Aydin, M. (2019). The relationship between energy consumption, economic growth, and CO2 emission in MENA countries: Causality analysis in the frequency domain. Energy, 168, 815-822. http s://doi.org/10.1016/i.energy.2018.11.139

Gorus, M. S., Ozgur, O., \& Develi, A. (2019). The relationship between oil prices, oil imports and income level in Turkey: Evidence from Fourier approximation. OPEC Energy Review, 43(3), 327-341. https://doi.org/10.1111/opec.12159

Jobert, T., \& Karanfil, F. (2007). Sectoral energy consumption by source and economic growth in Turkey. Energy Policy, 35(11), 5447-5456. https://do i.org/10.1016/j.enpol.2007.05.008

Kar, M., \& Kınık, E. (2008). An econometric analysis of the relationship between the types of electricity consumption and economic growth in Turkey. Afyon Kocatepe University Journal of Economics and Administrative Sciences, 10(2), 333-353.
Omri, A. (2014). An international literature survey on energy-economic growth nexus: Evidence from country-specific studies. Renewable and Sustainable Energy Reviews, 38, 951-959. https://doi.org/10.101 6/j.rser.2014.07.084

Ozturk, I. (2010). A literature survey on energygrowth nexus. Energy Policy, 38(1), 340-349. http s://doi.org/10.1016/j.enpol.2009.09.024

Şahbaz, A., \& Yanar, R. (2013). An Econometric Analysis of Relationship between Total and Sectoral Energy Consumption and Economic Growth in Turkey. Finans Politik \& Ekonomik Yorumlar, 50(575), 31-44.

Terzi, H. (1998). The relationship between electricity consumption and economic growth in Turkey: A sectoral comparison. İktisat, İşletme ve Finans, 13(144), 62-71.

Tiba, S., \& Omri, A. (2017). Literature survey on the relationships between energy, environment and economic growth. Renewable and Sustainable Energy Reviews, 69, 1129-1146. https://doi.org/10.1016/j.rse $\underline{r .2016 .09 .113}$

Usta, C., \& Berber, M. (2017). Sectoral analysis of relationship between energy consumption and economic growth in Turkey. International Journal of Economic \& Social Research, 13(1), 173-187. 